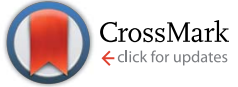

Cite this: RSC Adv., 2017, 7, 14348

\title{
Effects of microwaves on molecular arrangements in potato starch $\dagger$
}

\author{
Huijie Shen, ${ }^{a}$ Daming Fan, ${ }^{\text {a }}$ Luelue Huang, $^{\mathrm{c}}$ Yishu Gao, ${ }^{\mathrm{a}}$ Huizhang Lian, ${ }^{\mathrm{b}}$ \\ Jianxin Zhao and Hao Zhang ${ }^{a}$
}

The effects of microwave heating on the molecular arrangements in potato starch, including single and double helices and amorphous structures, were studied using a ${ }^{13} \mathrm{C} C P / M A S ~ N M R$ method combined with X-ray diffraction. Rapid heating in an oil bath and conventional slow heating were used as controls. During the microwave heating process, the double helical structures, the $V$-single and the crystallinity of potato starch exhibited similar changes to those observed when heated using conventional methods, although there were some differences. The effects on the structures were most pronounced when using conventional slow heating, followed by microwave heating, then conventional rapid heating. Both the rapid heating and electromagnetic effects of microwaves on potato starch, influenced the nature of the amorphous and double helical structures; although the rapid heating effect was greater. Conventional slow heating resulted in the thorough gelatinisation of starch.

Received 11th December 2016 Accepted 27th February 2017

DOI: $10.1039 / c 6 r a 28048 j$

rsc.li/rsc-advances affect the external shape of normal and waxy corn starch. However, cavities were formed in the structure of the granules, and the crystalline type of high-amylose corn starch was changed from A + B to B. ${ }^{7}$ The chemical structure of starch and its derivatives are similar. Derivatives differ only in the number of repeating units or the order of atomic arrangement. However, few studies have examined the changes to the amorphous, single and double helix structures within starch granules, during gelatinisation when heated with microwave radiation.

Microwave heating differs from traditional convection heating: materials absorb microwave energy and this energy is subsequently converted into heat through molecular vibration and friction. ${ }^{8}$ The mechanisms about how microwave heating affects starch granules still remain unclear. There may be some special microwave effects in addition to rapid heating effect according to a series of phenomena found in the current study of microwave reaction, and these two effects may also act on the material and then influence physical and chemical properties and structure of materials. ${ }^{9}$ However, some researchers deny the existence of special effect of microwave. ${ }^{10}$

In this study, we evaluated the effect of different heating methods on the amorphous, single and double helix structures and the relative crystallinity of potato starch using ${ }^{13} \mathrm{C} \mathrm{CP} / \mathrm{MAS}$ NMR and X-ray diffraction. The starch samples that underwent rapid heating were compared with samples heated using a conventional slow heating method to examine rapid heating effect of microwave. Rapid heating in an oil bath was used to simulate the special effect of a microwave, and thereby to investigate the thermal and electromagnetic effects of microwave heating on the structure of starch.
${ }^{a}$ State Key Laboratory of Food Science and Technology, School of Food Science and Technology, Jiangnan University, Wuxi 214122, China. E-mail: fandm@jiangnan. edu.cn; Fax: +860510 85912155; Tel: +86 051085884620

${ }^{b}$ Wuxi Huashun Minsheng Food Co. Ltd., Wuxi 214218, China

${ }^{c}$ School of Applied Chemistry and Biological Technology, Shenzhen Polytechnic, Shenzhen 518055, China

$\dagger$ Electronic supplementary information (ESI) available. See DOI: 10.1039/c6ra28048j 


\section{Materials and methods}

\section{Materials}

Potato starch (protein content $0.23 \%$, starch content $94.22 \%$, amylose content of $13.62 \%$, water content $5.5 \%$, particle size of $38.55 \pm 2.48 \mu \mathrm{m}$, weight-average molar mass of $5.048 \times 10^{7} \mathrm{~g}$ $\mathrm{mol}^{-1}$ ) was from Fengning Shuangxin Agricultural Development Co., Ltd. The onset gelatinization temperature $\left(T_{\mathrm{o}}\right)$ of potato starch was $57.16+0.11{ }^{\circ} \mathrm{C}$.

The water content would affect the dielectric properties of starch samples and further enhance the effect of microwave on starch. ${ }^{\mathbf{1 1}}$ The permittivity $\left(\varepsilon^{\prime}\right)$ and dielectric loss factor $\left(\varepsilon^{\prime \prime}\right)$ of native starch with $5.5 \%$ water content is 3.04 and 0.23 respectively and the $\varepsilon^{\prime}$ and $\varepsilon^{\prime \prime}$ of $3 \%$ concentration of starch suspensions ( $97 \%$ water content) is 70.76 and 9.75 respectively, which indicates that the water significantly improves the dielectric properties of the system.

\section{Methods}

Preparation of microwave-treated samples (MS). ${ }^{\mathbf{1 2}} 3.00 \mathrm{~g}$ of potato starch was dispersed in $97.00 \mathrm{~g}$ of deionised water, to produce a $3 \%(\mathrm{w} / \mathrm{w})$ starch solution. The solution was heated in a mono mode microwave synthesiser (Milestone, Italy) set at $1000 \mathrm{~W}$. An optical fibre temperature probe (FISO Technologies Inc, Québec, Canada) was used to measure the temperature of the starch sample during the heating process; and the change in temperature over time was recorded.

Preparation of samples via rapid heating in an oil bath (RS). The $3 \%(\mathrm{w} / \mathrm{w})$ potato starch solution was heated in a Thermo Scientific AC200 oil bath (Pierce, Illinois, USA). The change in temperature over time was recorded using an optical fibre temperature probe. The microwave power and oil temperature were altered until their temperature curves coincided.

The starch samples were heated by microwave or oil bath to $45{ }^{\circ} \mathrm{C}, 55{ }^{\circ} \mathrm{C}, 60{ }^{\circ} \mathrm{C}, 65{ }^{\circ} \mathrm{C}$ and $75{ }^{\circ} \mathrm{C}$ in quartz reactor under mechanical agitation with a stirrer to ensure uniform heating before being cooled with ice bath and lyophilised. Each dried starch sample was crushed, and then powdered by passing it through a $75 \mu \mathrm{m}$ sieve.

Preparation of samples via a traditional slow heating method (SS). ${ }^{13}$ The $3 \%(\mathrm{w} / \mathrm{w})$ potato starch solution was heated on a hotplate (Xingshui Scientific Instrument Company, Tianjing, China), and the change in temperature over time was recorded using an optical fibre temperature probe. Completely gelatinized starch samples were passed through a $75 \mu \mathrm{m}$ m sieve after freeze-drying.

Preparation of samples in an amorphous state. Amorphous starch was prepared using a Rapid Visco-Analyzer (RVA) (Newport Scientific, Australia). A $3 \%(\mathrm{w} / \mathrm{v})$ potato starch solution was heated from $25{ }^{\circ} \mathrm{C}$ to $95{ }^{\circ} \mathrm{C}$ at a rate of $0.25{ }^{\circ} \mathrm{C} \mathrm{s}^{-1}$, maintained at $95{ }^{\circ} \mathrm{C}$ for 15 minutes, then cooled to $50{ }^{\circ} \mathrm{C}$ at a rate of $0.25{ }^{\circ} \mathrm{C}$ $\mathrm{s}^{-1}$. Completely gelatinised starch samples were freeze-dried, then passed through a $75 \mu \mathrm{m}$ sieve. The water content of the dried samples was approximately $10 \%$.

Water equilibration. A saturated $\mathrm{NaCl}$ solution was used to equilibrate the water content of the samples for two weeks at
$25{ }^{\circ} \mathrm{C}$, until the water activity of the samples $\left(a_{\mathrm{w}}=0.887\right)$ was constant and consistent.

\section{Analytical methods}

X-ray diffractometry. The relative crystallinity of the starch samples was measured by an X-ray diffractometer (XRD) ${ }^{1}(\mathrm{D} 8$, Bruker Co.) using copper $\mathrm{K} \alpha$ radiation. Powder samples, after water equilibration, were exposed to the X-ray beam $(40 \mathrm{kV}, 40$ $\mathrm{mA})$. The scanning region of the diffraction angle, $2 \theta$, was $3-36^{\circ}$, and the scanning rate was $0.02^{\circ} \mathrm{s}^{-1}$. Relative crystallinity was determined quantitatively according to Herman's method. ${ }^{\mathbf{1 4}}$

${ }^{13} \mathbf{C}$ CP/MAS NMR. The ${ }^{13} \mathrm{C}$ CP/MAS NMR spectra were recorded at room temperature at $100 \mathrm{MHz}$ using a Bruker AVIII400 equipped with a $7 \mathrm{~mm} \mathrm{CP} / \mathrm{MAS}$ detection probe (Bruker Instrument, Inc., Billerica, MA). The samples were spun at 20 $\mathrm{kHz}$, and 4096 scans were conducted for each spectrum. The spectral width was $38 \mathrm{kHz}$, and the contact time was $13 \mathrm{~ms}$. As per the method described by Tan et al.,${ }^{15}$ the Solver data analysis tool in Excel was used to calculate the decomposition rate of the spectra. Ordered subspectra were obtained by subtracting the subspectrum of the amorphous component from the original spectrum of the sample. PeakFit version 4 for Win 32 (Jandel Scientific Software, CA) was used to fit the peaks of the spectra. The proportions of double and single helical structures in the starch samples were calculated using the method of Tan et al.

\section{Results and discussion}

Comparing the three heating methods

As shown in Fig. 1A, the temperature curve resulting from microwave heating $(1000 \mathrm{~W})$ does not correlate with the temperature curve obtained from rapid heating in a $200{ }^{\circ} \mathrm{C}$ oil bath. A turning point was observed at $60{ }^{\circ} \mathrm{C}$ in the samples heated in the oil bath, and above this temperature the heating rate decreased. The microwave power level was altered such that the temperature curves of both methods were identical. The final temperature achieved through rapid heating in an oil bath was $200{ }^{\circ} \mathrm{C}$. The microwave apparatus was set at $1000 \mathrm{~W}$ for $70 \mathrm{~s}$, then $350 \mathrm{~W}$ for $50 \mathrm{~s}$ and $650 \mathrm{~W}$ for $125 \mathrm{~s}$. The heating curves obtained with the rapid oil bath and modified microwave methods are shown in Fig. 1B. The correlation coefficient of the two curves was calculated to be 0.9981 , and the heating rate of both methods was approximately $27.2^{\circ} \mathrm{C} \mathrm{min}^{-1}$. The temperature curve of the samples treated with the conventional slow heating method (with a heating rate of $4.68{ }^{\circ} \mathrm{C} \mathrm{min}^{-1}$ ) is shown in Fig. $1 \mathrm{C}$.

\section{Changes in crystallinity of starch samples measured by XRD}

As shown in Fig. 2, the crystallinity of each sample declined as soon as the heating processes were initiated. At temperatures below the gelatinisation temperature, the heat absorbed by the starch had little effect on the crystalline regions, as indicted by the slow decline in crystallinity below $60^{\circ} \mathrm{C}$. Furthermore, when the gelatinisation temperature was reached the mobility of the amorphous segments was increased, leading to instability in the starch granules. As heating continued, microcrystalline starch melted and the starch granules broke up, accompanied 

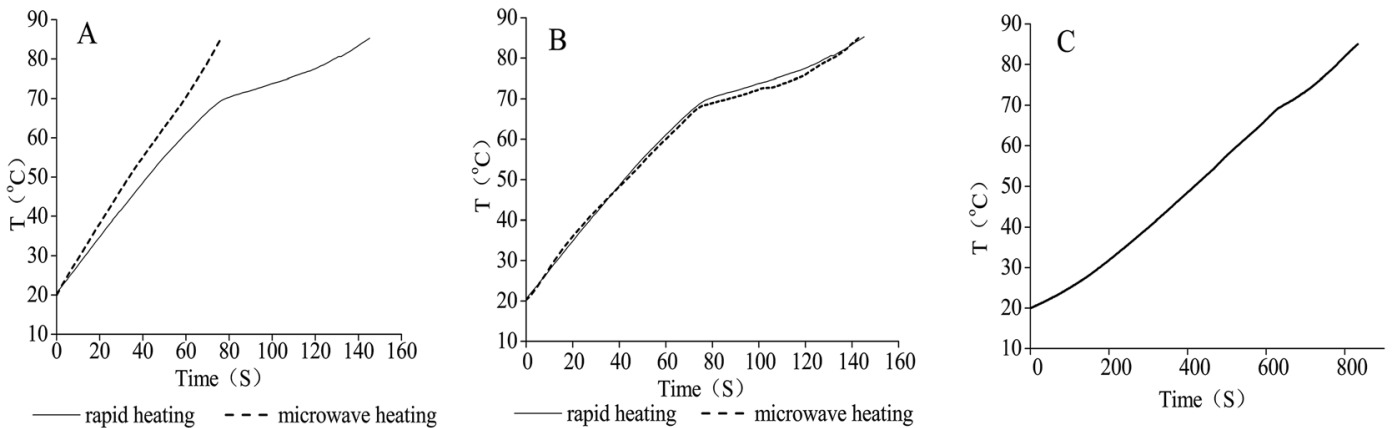

Fig. 1 (A) Temperature curves of the samples heated using a microwave $(1000 \mathrm{~W})$ and an oil bath $\left(200^{\circ} \mathrm{C}\right)$; (B) temperature curves of the samples heated using a microwave (1000 W for $70 \mathrm{~s} ; 350 \mathrm{~W}$ for $50 \mathrm{~s} ; 650 \mathrm{~W}$ for $125 \mathrm{~s})$ and an oil bath $\left(200^{\circ} \mathrm{C}\right)$; (C) temperature curve of the heated with the slow heating method.

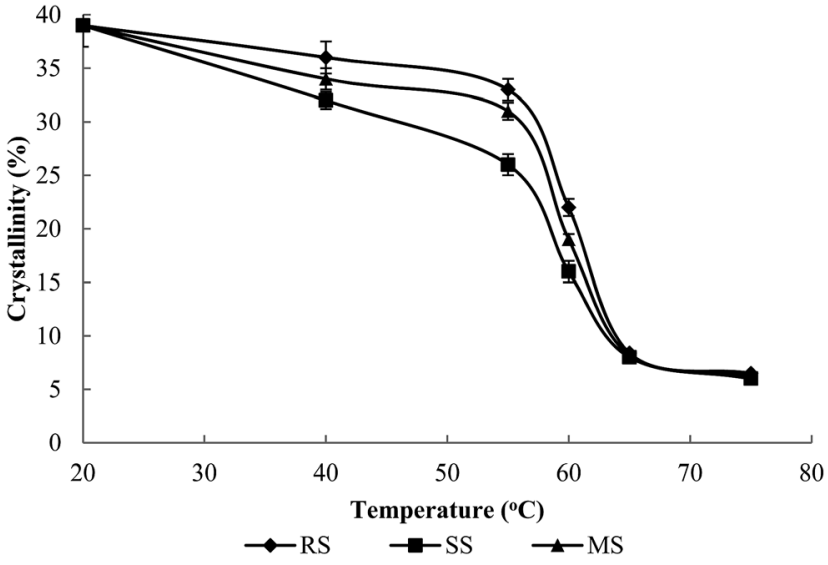

Fig. 2 Changes in the relative crystallinity of three potato starch samples with different heat treatment (RS, conventional rapid heating $(\bullet)$; SS, conventional slow heating ( $\mathbf{\square})$; MS, microwave heating ( $\boldsymbol{\Delta})$ ) were determined by $\mathrm{X}$-ray diffractometry.

by amylose leaching and double helices being opened, leading to amorphous paste formation. ${ }^{16}$ The gelatinisation temperature of potato starch is $60-65{ }^{\circ} \mathrm{C}$, which was confirmed by the significant reduction in crystallinity at this temperature, as shown in Fig. 2. Beyond this temperature the crystallinity declined far more slowly.

The SS exhibited a maximum decreases in crystallisation of $31.0 \%$, the MS showed a decrease of $30.8 \%$ and the minimum relative changes in crystallinity of RS decreased by $30.6 \%$.

\section{Structural changes determined by ${ }^{13} \mathrm{C}$ CP/MAS NMR}

Total analysis of the ${ }^{13} \mathrm{C}$ CP/MAS NMR spectra. Fig. $3 \mathrm{~A}-\mathrm{C}$ show the ${ }^{13} \mathrm{C} \mathrm{CP} / \mathrm{MAS}$ NMR spectra of raw and amorphous starch samples, and starch samples subjected to microwave heating, rapid heating in an oil bath and conventional slow heating, at $45,55,60,65$ and $75^{\circ} \mathrm{C}$. The chemical shifts of each major peak are presented in Table 1 . The chemical shifts were consistent with the results of previous studies. ${ }^{17}$ The signal at 94-105 ppm was assigned with $\mathrm{C} 1$, the signal at 58-65 ppm was assigned to $\mathrm{C} 6$ and the overlapping signal at 68-78 ppm was associated with C2, C3 and C5. The C1 signals in the NMR spectra contained information related to the crystalline and amorphous structures in the starch. ${ }^{18}$

Morrison et al. reported the ${ }^{13} \mathrm{C} \mathrm{CP} / \mathrm{MAS}$ NMR signal data of several $\mathrm{C}$ regions. The signals at 99-102 ppm in the $\mathrm{C} 1$ region (90-110 ppm) were found to contain information on the double helices, and the signals at 93-99 ppm were found to be several signals originating from the amorphous regions. The broad peak at 103 ppm contained information on the amorphous state of the starch. The C2, C3 and C5 regions (70-79 ppm) mainly originated from B-type double helices, whereas the $\mathrm{C} 4$ region (80-84 ppm) contained information on the amorphous regions and a small proportion of left-handed single-stranded V-type single helices. ${ }^{19}$

In A-type starch, maltotriose is the smallest repeating unit, and double helical structures are formed from two-fold axisymmetric helical structures, which produce a triplet in the C1 peak. In B-type starch, maltose is the smallest repeating unit,
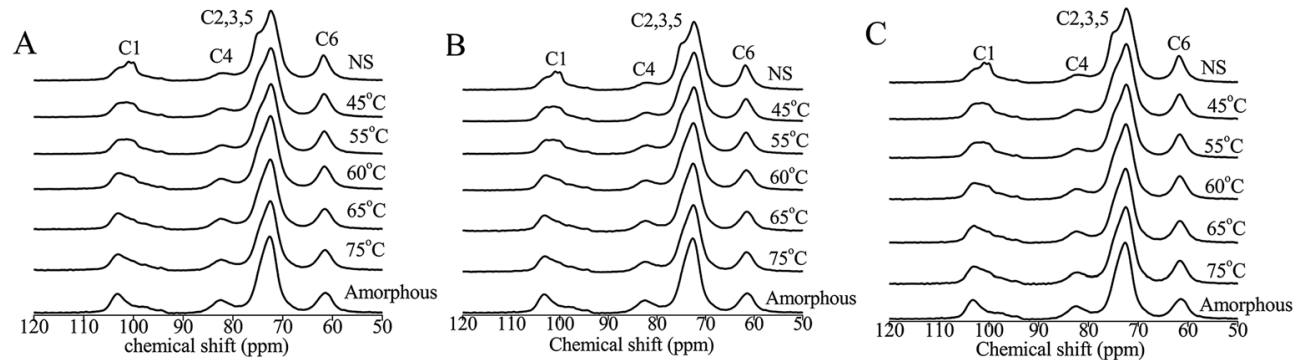

Fig. $3{ }^{13} \mathrm{C}$ CP/MAS NMR spectra of potato starch samples at different temperatures ((A) MS; (B) RS; (C) SS). Spectra of amorphous and raw starch (NS) samples included for comparison. 
Table $1{ }^{13} \mathrm{C}$ CP/MAS NMR chemical shifts of starch samples heated using three different heating methods

Chemical shift (ppm)

\begin{tabular}{|c|c|c|c|c|}
\hline Starch sample & $\mathrm{C} 1$ & $\mathrm{C} 2,3,5$ & $\mathrm{C} 4$ & C6 \\
\hline Raw (NS) & $94.42,98.18,100.94,102.87$ & $71.3,72.5,73.9$ & 82.6 & 61.9 \\
\hline Amorphous & 103.13 & $72.4,74.3$ & 82.3 & 61.5 \\
\hline $\mathrm{MS} 45^{\circ} \mathrm{C}$ & $94.39,98.68,101.57,103.55$ & $71.2,72.4,73.9$ & 82.6 & 61.5 \\
\hline $\operatorname{MS} 55^{\circ} \mathrm{C}$ & $94.33,98.65,99.37,100.95,103.67$ & $71.1,72.4,74.0$ & 82.0 & 61.2 \\
\hline $\mathrm{MS} 60^{\circ} \mathrm{C}$ & $94.35,98.57,99.32,100.57,103.52$ & $71.1,72.4,74.0$ & 82.3 & 61.2 \\
\hline $\operatorname{MS} 65^{\circ} \mathrm{C}$ & 103.55 & $71.2,72.5,73.9$ & 82.2 & 61.8 \\
\hline $\operatorname{MS} 75{ }^{\circ} \mathrm{C}$ & 103.51 & $71.4,72.5,74.0$ & 82.4 & 61.5 \\
\hline $\mathrm{RS} 45{ }^{\circ} \mathrm{C}$ & $94.39,98.68,101.57,103.55$ & $72.4,74.1$ & 81.9 & 61.4 \\
\hline $\mathrm{RS} 55^{\circ} \mathrm{C}$ & $94.31,98.45,99.57,100.98,103.62$ & $72.4,74.0$ & 82.6 & 61.5 \\
\hline $\mathrm{RS} 60^{\circ} \mathrm{C}$ & $94.57,98.17,99.49,100.47,103.54$ & $71.4,72.5,73.6$ & 82.7 & 61.5 \\
\hline $\mathrm{RS} 65{ }^{\circ} \mathrm{C}$ & 102.78 & $71.2,72.5,73.9$ & 82.5 & 61.7 \\
\hline $\mathrm{RS} 75{ }^{\circ} \mathrm{C}$ & 103.17 & $71.1,72.5,74.2$ & 82.5 & 61.6 \\
\hline $\mathrm{SS} 45^{\circ} \mathrm{C}$ & $94.52,98.68,101.67,103.41$ & $71.2,72.4,74.0$ & 82.5 & 61.5 \\
\hline $\mathrm{SS} 55^{\circ} \mathrm{C}$ & $94.28,98.48,99.39,100.20,103.64$ & $71.2,72.4,74.0$ & 82.0 & 61.9 \\
\hline $\mathrm{SS} 60{ }^{\circ} \mathrm{C}$ & $94.76,98.20,99.47,100.71,103.57$ & $72.4,74.1$ & 82.1 & 61.5 \\
\hline $\mathrm{SS} 65{ }^{\circ} \mathrm{C}$ & 102.95 & $72.4,74.0$ & 82.6 & 61.8 \\
\hline $\mathrm{SS} 75{ }^{\circ} \mathrm{C}$ & 103.37 & $71.1,72.4,74.0$ & 82.5 & 61.5 \\
\hline
\end{tabular}

and double helical structures are formed from three-fold screw axes, which produce a doublet in the $\mathrm{C} 1$ peak. ${ }^{18}$ As shown in Fig. 3, double peaks were observed in the $\mathrm{C} 1$ region, indicating that the double helical structures in potato starch are B-type double helices. This was consistent with the results of previously reported studies. ${ }^{20,21}$ As the heating duration increased, the crystalline type of potato starch transformed gradually from A-type to B-type, which is consistent with previous reports. ${ }^{20}$

The signal from the triplet peak gradually diminished with heating, and only a single peak around 103 ppm in the C1 region was observed in the spectrum of the highest temperature sample, suggesting that potato starch had started the gelatinisation process. With all three heating methods, at temperatures above $65{ }^{\circ} \mathrm{C}$ the spectra were similar to the spectrum of fully gelatinised amorphous starch. This finding indicated that the gelatinisation temperature range of the potato starch was consistent between all three heating methods. The relative intensities of the signals in the $\mathrm{C} 4$ region increased with increasing temperature. These data suggest that the amorphous content in the starch granules substantially increased with temperature, which resulted in a higher level of gelatinisation.

We found that the temperature points at which the triplet peaks changed into doublet peaks, the weak signal intensity of the triplet peaks and the increase in the signal strength in the C4 region were the same in all three sets of samples.

\section{Changes in the single and double helical and amorphous structures of the starch samples}

Ihwa et al. improved the ${ }^{13} \mathrm{C}$ NMR method, and used it to determine the proportion of double helices, amorphous structures and V-type single helices. ${ }^{15}$ In this study, the Solver data analysis tool was used to obtain the subspectra of the amorphous content in the samples at different temperatures, based on the ${ }^{13} \mathrm{C}$ NMR spectra. An ordered subspectrum was obtained by subtracting the subspectrum of the amorphous component from the original spectrum of the sample. For example, Fig. 4 shows the three subspectra of the MS sample at different temperatures. Sub-peak fitting of ordered and disordered structures was performed on the subspectra, using PeakFit software. A combination (50/50) of Lorentzian and Gaussian profiles produced acceptable curve fitting $\left(r^{2} \geq 0.9990\right)$.

As shown in Fig. 4, the intensity and area of the spectra of the amorphous structures gradually increased with temperature, while the intensity and area of the spectra of the ordered structures declined. The subspectra of the ordered structures were weak and highly unstable at temperatures higher than $65{ }^{\circ} \mathrm{C}$.

The peak fitting results for the ordered subspectra of MS are shown in Fig. 5, and the calculated proportions of amorphous, single and double helix structures are summarised in Table 2.

As shown in Table 2, the samples exhibited similar trends in the changing proportions of amorphous, double helices and Vtype single helices, regardless of the heating method and all changed with the rising temperature, especially when the temperature was near the gelatinization point. At temperatures below $60{ }^{\circ} \mathrm{C}$, the proportions of amorphous regions and double helices changed very slowly; however, the changes in the SS samples were $6 \%$ and $10 \%$, respectively, slightly greater than those in the MS (around 4\% and 7\%) and RS (around 1\% and $3.5 \%$ ) samples. In all of the samples, when the temperature rose above $60{ }^{\circ} \mathrm{C}$ the proportion of double helices decreased rapidly, while the proportion of amorphous regions increased rapidly and the proportion of V-type single helices decreased to zero before the end of the experiment. At $75{ }^{\circ} \mathrm{C}$, the proportion of double helices in the RS, MS and SS samples decreased by $20 \%$, $22 \%$ and $24 \%$, respectively. The amorphous content of RS, MS and SS increased by $27 \%, 29 \%$ and $30 \%$, respectively.

Using these results, we can predict both the thermal and special effects of microwaves on the proportion of amorphous region, double helices and V-type single helices in potato starch. 

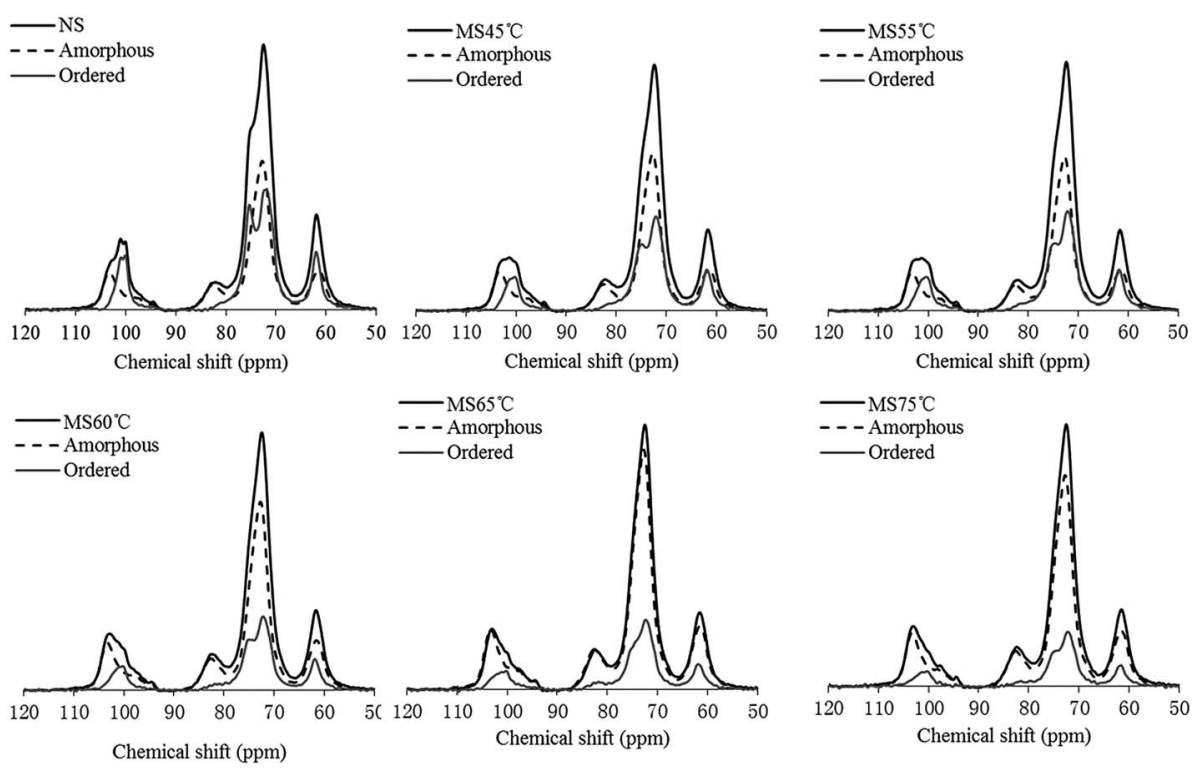

Fig. 4 Deconvolution of the MS ${ }^{13}$ C CP/MAS NMR spectra (-) into the amorphous (-- -) and ordered (-) phases. The Solver data analysis tool in Excel was used to calculate the deconvolution. An ordered subspectrum was obtained by subtracting the subspectrum of the amorphous component from the original spectrum of the sample. The spectra of the other two samples are contained in the ESI. $\dagger$
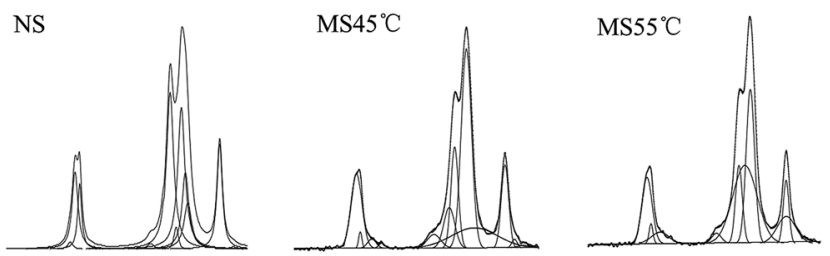

$\mathrm{MS} 60^{\circ} \mathrm{C}$

$\mathrm{MS} 65^{\circ} \mathrm{C}$
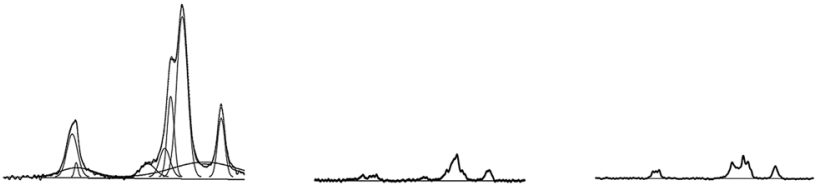

Fig. 5 Peak fitting results of the subspectra of ordered structures in MS samples. The number following 'MS' indicates the temperature that the samples were heated to. PeakFit version 4 for Win 32 (Jandel Scientific Software, CA) was used to fit the peaks of the ordered spectra shown in Fig. 4. The proportions of double and single helical structures in the starch samples were calculated using the method of Tan et al. The spectra of the other two samples are in the ESI. $\dagger$

At the beginning of the microwave treatment, the destruction of the internal structure of the starch had not commenced, and thus the structure was relatively stable. When the temperature exceeded $60^{\circ} \mathrm{C}$, the hydration and particle swelling rates of the starch rapidly increased, as a large quantity of water molecules entered the starch granules. During this period, the heating rates of the MS and RS samples slowed down, but remained greater than the heating rate of the SS sample. The heating time of the MS and RS samples were correspondingly short. This may be the cause of the lower degrees gelatinisation in the MS and RS samples.
Table 2 Proportions of amorphous, double helical and V-type single helical structures in starch samples treated with three different heating methods

\begin{tabular}{llll}
\hline Sample & $\begin{array}{l}\text { Amorphous } \\
\text { content }(\%)\end{array}$ & $\begin{array}{l}\text { Single helix } \\
\text { content }(\%)\end{array}$ & $\begin{array}{l}\text { Double helix } \\
\text { content }(\%)\end{array}$ \\
\hline Raw starch & 58.71 & 7.08 & 34.21 \\
MS45 ${ }^{\circ} \mathrm{C}$ & 61.82 & 5.93 & 32.25 \\
MS55 ${ }^{\circ} \mathrm{C}$ & 65.67 & 3.40 & 30.93 \\
MS60 ${ }^{\circ} \mathrm{C}$ & 77.94 & 1.30 & 20.76 \\
MS65 ${ }^{\circ} \mathrm{C}$ & 85.81 & 0 & 14.19 \\
MS75 ${ }^{\circ} \mathrm{C}$ & 87.99 & 0 & 12.01 \\
RS45 ${ }^{\circ} \mathrm{C}$ & 58.06 & 6.27 & 35.67 \\
RS55 ${ }^{\circ} \mathrm{C}$ & 62.83 & 3.70 & 33.47 \\
RS60 ${ }^{\circ} \mathrm{C}$ & 74.47 & 1.83 & 23.70 \\
RS65 ${ }^{\circ} \mathrm{C}$ & 83.96 & 0 & 16.04 \\
RS75 ${ }^{\circ} \mathrm{C}$ & 85.57 & 0 & 14.43 \\
SS45 ${ }^{\circ} \mathrm{C}$ & 65.43 & 5.54 & 29.03 \\
SS55 ${ }^{\circ} \mathrm{C}$ & 68.22 & 2.13 & 29.65 \\
SS60 ${ }^{\circ} \mathrm{C}$ & 84.77 & 0.87 & 14.36 \\
SS65 ${ }^{\circ} \mathrm{C}$ & 87.45 & 0 & 12.55 \\
SS75 ${ }^{\circ} \mathrm{C}$ & 89.93 & 0 & 10.07
\end{tabular}

\section{Conclusions}

Three heating methods were established as a model to study the effects of microwaves on molecular arrangements. We carried out ${ }^{13} \mathrm{C} \mathrm{CP} / \mathrm{MAS}$ NMR combined with $\mathrm{X}$-ray to detect the proportions of amorphous structures, double helices and V-type single helix structures changes in potato starch. Compared with native potato starch, the amorphous content of microwave heating samples increased $29 \%$, the double helix structure decreased by $22 \%$, and the relative crystallinity of potato starch after microwave heating decreased by $30.8 \%$, which were all between rapid heating and slow heating sample. From these 
results, we determined that both the rapid heating and electromagnetic effects of microwaves influenced the proportion of amorphous and double helical structures, and that rapid heating had a greater effect than the electromagnetic effects. Additionally, microwave special effects may strengthen and accelerate the change from ordered to disordered structures.

\section{Conflicts of interest}

The authors declare that they have no conflicts of interest.

\section{Abbreviations used}

$\begin{array}{ll}\text { NS } & \text { Native potato starch sample } \\ \text { MS } & \text { Microwave-heated potato starch sample } \\ \text { RS } & \text { Rapidly heated potato starch sample } \\ \text { SS } & \text { Slowly heated potato starch sample }\end{array}$

\section{Acknowledgements}

This research was supported by "Five-Twelfth" National Science and Technology Support Program (Grant No. 2014BAD04B03), National Natural Science Foundation of China (Grant No. 31301504, 31571879), and Technological Innovation and Industrial Upgrading Program of Wuxi (Grant No. WX0302B0105-041500-07).

\section{References}

1 J. L. Jane, K. S. Wong and A. E. McPherson, Carbohydr. Res., 1997, 300, 219-227.

2 P. A. M. Steeneken and A. J. J. Woortman, Carbohydr. Res., 1994, 258, 207-221.

3 M. J. Gidley and S. M. Bociek, J. Am. Chem. Soc., 1985, 107, 7040-7044.

4 M. J. Gidley and S. M. Bociek, J. Am. Chem. Soc., 1988, 110, 3820-3829.

5 G. Lewandowicz, J. Fornal and A. Walkowski, Carbohydr. Polym., 1997, 34, 213-220.
6 A. Szepes, M. Hasznos-Nezdei, J. Kovacs, Z. Funke, J. Ulrich and P. Szabo-Revesz, Int. J. Pharm., 2005, 302, 166-171.

7 Z. G. Luo, X. W. He, X. Fu, F. X. Luo and Q. Y. Gao, StarchStärke, 2006, 58, 468-474.

8 D. M. Fan, W. R. Ma, L. Y. Wang, J. L. Huang, F. M. Zhang, J. X. Zhao, H. Zhang and W. Chen, Carbohydr. Polym., 2013, 92, 1395-1401.

9 A. Loupy, F. Maurel and A. Sabatie-Gogova, Tetrahedron, 2004, 60, 1683-1691.

10 E. J. Dominic, M. Lopez and B. Thomas, J. Chem. Sci., 2007, 119, 47-51.

11 R. Torrealbameléndez, M. E. Sosamorales, J. L. Olveracervantes and A. Coronachávez, Int. J. Food Prop., 2015, 19, 564-577.

12 G. E. Vandeputte, R. Vermeylen, J. Geeroms and J. A. Delcour, J. Cereal Sci., 2003, 38, 43-52.

13 J. A. Putseys, C. J. Gommes, P. Van Puyvelde, J. A. Delcour and B. Goderis, Carbohydr. Polym., 2011, 84, 1141-1150.

14 P. H. Hermans and A. Weidinger, J. Appl. Phys., 1948, 19, 491-506.

15 I. Tan, B. M. Flanagan, P. J. Halley, A. K. Whittaker and M. J. Gidley, Biomacromolecules, 2007, 8, 885-891.

16 T. A. Waigh, M. J. Gidley, B. U. Komanshek and A. M. Donald, Carbohydr. Res., 2000, 328, 165-176.

17 M. Urbanova, A. Sturcova, J. Brus, H. Benes, E. Skorepova, B. Kratochvil, J. Cejka, I. Sedenkova, L. Kobera, O. Policianova and A. Sturc, J. Pharm. Sci., 2013, 102, 12351248.

18 F. Delval, G. Crini, S. Bertini, N. Morin-Crini, P. M. Badot, J. L. Vebrel and G. Torri, J. Appl. Polym. Sci., 2004, 93, 2650-2663.

19 W. R. Morrison, R. V. Law and C. E. Snape, J. Cereal Sci., 1993, 18, 107-109.

20 W. Blaszczak, S. Valverde and J. Fornal, Carbohydr. Polym., 2005, 59, 377-383.

21 S. Mathur, R. Vyas, K. Sachdev and S. K. Sharma, J. Non-Cryst. Solids, 2011, 357, 1632-1635. 